\title{
Socio-economic status and maternal BMI are associated with duration of breast-feeding of Norwegian infants
}

\author{
Vilde K Bjørset, Christine Helle, Elisabet R Hillesund and Nina C Øverby* \\ Department of Public Health, Sport and Nutrition, Faculty of Health and Sport Sciences, University of Agder, PO Box \\ 422, 4604 Kristiansand, Norway
}

Submitted 18 October 2017: Final revision received 19 November 2017: Accepted 27 November 2017: First published online 23 January 2018

\begin{abstract}
Objective: To explore whether there is an association between socio-economic status and maternal BMI and duration of any breast-feeding/exclusive breastfeeding among Norwegian infants at 4 and 5 months of age in 2016.

Design: Cross-sectional design. Baseline data from a randomized controlled trial. Data concerning breast-feeding were collected by FFQ.

Setting: Recruitment was done at child health-care centres and through Facebook in 2016. In total, 960 infants/parents registered for participating in the study Early Food for Future Health.

Subjects: A total of 715 infant/mother dyads completed the questionnaire when the child was between 5 and 6 months old.

Results: At 5 months of age, $81.0 \%$ of infants were breast-fed and $16.4 \%$ were exclusively breast-fed. Infants of highly educated mothers had higher odds of being breast-fed at 5 months compared with infants of mothers with less education. Infants of multiparous mothers had higher odds of being exclusively breast-fed for the first 5 months compared with infants of mothers with one child. Infants of mothers with overweight/obesity had reduced odds of both being breast-fed at all and being exclusively breast-fed at 4 months of age compared with infants of mothers with normal BMI.

Conclusions: Our results show that duration of breast-feeding varies with socioeconomic status and maternal BMI in Norway. Targeting groups with low socioeconomic status and mothers with overweight or obesity is important, as they are less likely to breast-feed according to recommendations.
\end{abstract}

\author{
Keywords \\ Breast-feeding \\ Exclusive breast-feeding \\ Socio-economic factors \\ Maternal BMI
}

Exclusive breast-feeding is recommended during the first months of life to secure adequate nutrition for infants. Breast milk provides all nutrients required for the infant, except vitamin $\mathrm{D}^{(1)}$. Breast milk also contains hormones and enzymes that affect physiological maturing ${ }^{(2)}$, and protects infants against respiratory infection and diarrhoea $^{(3)}$. Long-term benefits from breast-feeding include reduced risk of obesity and type 2 diabetes in later life, and higher odds of increased intelligence ${ }^{(4)}$. For the mother, exclusive breast-feeding may help her to regain original weight ${ }^{(5)}$ and reduce the risk for ovarian and breast cancer ${ }^{(6,7)}$. For society, breast-feeding is one of the most cost-effective investments a nation can make ${ }^{(8)}$. Still, according to WHO, there is no country in world that fully adheres to the given breast-feeding recommendations.

Norwegian health authorities recommend that infants should be exclusively breast-fed for the first 4 to 6 months of life depending on the mother's and infant's needs, followed by a gradual introduction of foods in parallel with continued breast-feeding ${ }^{(9)}$. Before 2016, Norwegian mothers were recommended to breast-feed exclusively for the first 6 months of life ${ }^{(10)}$. These recommendations were adjusted in 2016, however, after the subjects had participated in the current study. Breast-feeding initiation rates are high (99\%) in Norway compared with other nations ${ }^{(11)}$. Despite long paid maternity leave for 46 or 56 weeks, depending on 100 or $80 \%$ degree of wage coverage respectively ${ }^{(12)}$, exclusive breast-feeding rates at 6 months are low in Norway. The latest national crosssectional study on infant nutrition from 2013 showed that $17 \%$ were exclusively breast-fed at 5.5 months ${ }^{(13)}$. For Norwegian immigrants these numbers were even lower. Only $7 \%$ of Norwegian-Somali and $10 \%$ of NorwegianIraqi infants were exclusively breast-fed at 4 months of age ${ }^{(14)}$.

Socio-economic factors such as maternal education and lifestyle variables like maternal smoking are associated 
with duration of breast-feeding and exclusive breastfeeding ${ }^{(15)}$. Norwegian public health policy aims to reduce the social gap in health ${ }^{(16)}$. A long maternity leave is established inter alia to enable breast-feeding for all infants regardless of their mother's socio-economic status. Previous studies have shown that people with higher socio-economic status breast-feed longer than people with lower socio-economic status ${ }^{(17)}$. This contributes to maintaining the social gradient in health, based on the documented health benefits of breast-feeding.

The Norwegian health authorities have recently launched a specific goal to increase the exclusive breastfeeding rate at 4 months to $60 \%{ }^{(18)}$. A national study on breast-feeding with data from 2013 shows that there has been no improvement in breast-feeding duration from early $2000^{(14)}$. To reach such high breast-feeding rate one needs to explore predictors of breast-feeding. Newer data are needed to explore whether there is a social gap in duration of exclusive breast-feeding and any breast-feeding, respectively, of Norwegian infants in 2016. Further, the socio-economic variables that have been investigated have mostly been limited to education and smoking.

There is a general lack of acknowledgment of obesity issues related to breast-feeding and breast-feeding duration $^{(18)}$. Worldwide, $40 \%$ of women aged 18 years or older are overweight and $15 \%$ are obese ${ }^{(19)}$. In Norway, $24 \%$ of woman aged 25-44 years are overweight and $10 \%$ are obese ${ }^{(20)}$. Both the WHO and Norwegian public health policy have addressed overweight as one of the main risk factors of premature death ${ }^{(16,21)}$. Overweight and obesity have health consequences across the life cycle, with an increased risk of non-communicable diseases ${ }^{(19)}$. One of the health implications related to maternal overweight and obesity is the seemingly lower ability to initiate and sustain breast-feeding ${ }^{(22)}$. Due to the growing epidemic of overweight, we wanted to include maternal BMI in the analyses to explore whether this association is present in a recent Norwegian population ${ }^{(22,23)}$.

The baseline data from the randomized controlled trial Early Food for Future Health was used to explore associations between socio-economic factors and maternal BMI, respectively, and duration of any breast-feeding/ exclusive breast-feeding during the infants' first 5 months of life.

\section{Methods}

\section{Subjects and design}

In 2016, Norwegian parents were invited to participate in the Early Food for Future Health study. Parents were eligible to participate if they had a 3-5-month-old infant, were literate in Norwegian and were responsible for providing food to their infant. Parents with infants aged 3-5 months were recruited through posting an information site and video on social media. All Norwegian health centres were informed about the study, including public health nurses who could inform mothers about the study. Parents consented to participate on an information site, and were subsequently sent an email with a link to a questionnaire when the infant had reached 5 months of age. Questionnaire data were collected between March 2016 and October 2016.

Among the 1048 participating parents, there were 960 unique infants (some had registered their infant several times). Of these, 718 parents completed the questionnaire (74.8\%). Baseline data from both the intervention and the control group were used in the current analyses. A sample of 718 Norwegian infants aged 5-6 months was established. After the duplicates were removed there were only three fathers left. These were excluded from the present study, leaving the total number of participants at 715 mother/infant dyads.

The Norwegian Centre for Research Data evaluated the study and informed consent was obtained from mothers/ parents.

\section{$\boldsymbol{F F Q}$}

An FFQ was developed for the Early Food for Future Health study to assess daily food consumption, breastfeeding duration and age at introduction of solid foods. Parents were asked to complete the questionnaires when their infant was between 5 and 6 months old.

Questions about breast milk and other liquids were asked as follows: "What kind of food and drinks has the infant received the first 6 months of life? Tick the box for each month $(0,1,2,3,4,5,6)$ the infant has received the listed foods and drinks' (breast milk, formula, water, juice, baby porridge, dinner, fruits/berries). Month 0 represents the time before the age of 1 month whereas month 1 represents 1 month of age and so forth.

Parents responded to questions concerning time of introduction of complementary foods as 'How old was your infant when he/she first was introduced for these foods?' (porridge, industrial and homemade; mashed vegetables, industrial and homemade; mashed fruits, industrial and homemade; meals with red/white meat or fish, industrial and homemade; and bread). Response alternatives were given in months.

All presented variables above were included when calculating exclusive breast-feeding duration.

\section{Socio-economic status}

Socio-economic status was measured with six different questions. (i) Education level, categorized as less than lower secondary school, upper secondary school, college/ university up to 4 years, and college/university more than 4 years. This variable was subsequently recoded into high or low education level (college/university education or not). (ii) Main activity/main activity before 
maternity leave had ten different categories (working full-time; working part-time; student; unemployed; homemaker; sick leave; disability benefits; leave; rehabilitation; other). These were recoded into working full-time, part-time, student and not working. (iii) Size at nearest urban area was reported in four categories: $\leq 4999,5000$ 14999, 15000-49999, $\geq 50000$ people. (iv) Geographic region was reported as nineteen different regions which were recoded into capital, East, South, West, Middle and North regions. (v) Ability to pay an unforeseen expense of 3000 NOK was categorized as 'yes', 'no' and 'maybe'. These were recoded into 'yes' and 'no/maybe'. (vi) The last question asked if participants had experienced difficulties paying their rent, food or transportation costs during the last 6 months. Possible responses were 'sometimes', 'often' or 'never', subsequently recoded into 'difficulties' and 'no difficulties'. In addition, we included one question regarding parental mother tongue, as an indicator of being native or not: 'Do you or the other parent have another mother tongue than Norwegian?' Responses were 'yes' or 'no'.

\section{Maternal BMI}

BMI is calculated as a person's weight in kilograms divided by the square of his/her height in metres $\left(\mathrm{kg} / \mathrm{m}^{2}\right)$. Underweight is defined as BMI less than $18.5 \mathrm{~kg} / \mathrm{m}^{2}$, and normal BMI is defined as BMI between 18.5 and $25 \mathrm{~kg} / \mathrm{m}^{2}$. Overweight is defined as BMI equal to or greater than $25 \mathrm{~kg} / \mathrm{m}^{2}$ and obesity is defined as BMI equal to or greater than $30 \mathrm{~kg} / \mathrm{m}^{2(24)}$. Maternal BMI was coded according to these cut-offs into four categories: normal, underweight, overweight and obese.

\section{Covariates}

The questionnaire also included sociodemographic variables such as parental age (reported as a continuous variable), gestational age (after age 38 weeks) and parity. A woman's parity is defined as the number births ${ }^{(25)}$. In the present paper, parity was categorized as 1,2 or $\geq 3$ births.

We included smoking as a lifestyle variable in our study. The response categories for parents' smoking status were 'no, never', 'no, but quitted', 'yes, but not daily' and 'yes, daily'. These response categories were recoded into 'no' and 'yes'. We also included physical activity, which was assessed with the following question: 'How many times a week are you physically active to the extent of being out of breath or sweating?' Response alternatives were 'never', 'less than once a week', 'twice a week', '3-4 times per week' and ' 5 times or more per week'. This variable was subsequently dichotomized into $\leq 2$ times/week and $\geq 3$ times/week.

\section{Definition of breast-feeding}

Being exclusively breast-fed at a given age is defined as receiving only breast milk and not being introduced to any other liquids or foods. Vitamin supplements, supplements and cod-liver oil do not affect exclusive breast-feeding status $^{(26)}$. Being breast-fed at a given age is defined as receiving breast milk, either given exclusively or with supplementary foods and/or drinks. Breast-feeding was categorized into exclusive breast-feeding and any breastfeeding in the present paper. The variable 'exclusively breast-fed' was constructed in SPSS. Duration of exclusive breast-feeding was calculated as the consecutive months the infant had received breast milk, without being introduced to any other liquids or foods. For example, an infant would be exclusively breast-fed at 5 months of age if having received breast milk at 5 months of age, without any other foods or liquids at any age point up to 5 months of age.

\section{Data analysis}

Associations between socio-economic factors and maternal BMI, respectively, and duration of exclusive breastfeeding and any breast-feeding were assessed at 4 and 5 months of age.

Predictor variables were selected based on earlier studies, and socio-economic variables that were thought to affect breast-feeding and exclusive breast-feeding were included. Univariate tests where the $P$ value was less than $0 \cdot 1$ were considered candidates for the adjusted model. The following variables were included: maternal age, maternal education, marital status, parity, maternal BMI, degree of urbanization, geographic region, ability to pay an unforeseen expense of 3000 NOK, difficulties with running expenses, smoking status, whether mother/father had mother tongue other than Norwegian and physical activity. There were different variables included in the different models, as only the variables from the univariate model with $P$ value of less than $0 \cdot 1$ were selected for each model. Maternal education and maternal age are two well-known predictors of breastfeeding and exclusive breast-feeding ${ }^{(15,27,28)}$, and were therefore included in all analyses regardless of their statistical significance level in the univariate tests. Potential violations of multicollinearity assumptions were tested by treating the categorical values as continuous in a linear regression and collinearity diagnostics were performed. Since we were not able to evaluate under-reporting or over-reporting of infant diet, the participants' responses regarding infant diet were kept as originally reported in the analysis.

The outcome variables (exclusive breast-feeding and any breast-feeding) are categorical. The predictor variables are dichotomous and categorical. Binary logistic regression analyses were used to examine factors that contribute to breast-feeding and exclusive breast-feeding. A two-tailed 5\% level of significance was used. Results were presented as OR with $95 \%$ CI.

All statistical analyses were conducted using the statistical software package IBM SPSS Statistics version 24. 


\section{Results}

Table 1 presents selected characteristics of the infants and their mothers. The gender distribution among the infants was almost $50 \%$. About $80 \%$ of mothers had college/ university education and $36.5 \%$ were physically active three times or more weekly. Almost $13 \%$ of the parents had a mother tongue other than Norwegian. Only $3 \cdot 8 \%$ of the mothers smoked. The proportion of exclusively breastfed infants the first month of life (age $=0$ months) was $73.6 \%$, at 4 months it decreased to $52.7 \%$, and at 5 months it dropped to $16 \cdot 4 \%$ (Fig. 1). The proportion of infants who were breast-fed but not necessarily exclusively

Table 1 Characteristics of infants and their mothers $(n 715)$, Early Food for Future Health study, March-October 2016

\begin{tabular}{|c|c|}
\hline Characteristic & $\%$, mean or sD $\dagger$ \\
\hline \multicolumn{2}{|l|}{ Infants } \\
\hline Boys/girls & $50 \cdot 8 / 49 \cdot 2$ \\
\hline \multicolumn{2}{|l|}{ Birth weight $(\mathrm{g})$} \\
\hline Mean & 3580 \\
\hline SD & 492 \\
\hline$>3500$ & $55 \cdot 7$ \\
\hline $2500-3500$ & $42 \cdot 9$ \\
\hline$<2500$ & 1.4 \\
\hline \multicolumn{2}{|l|}{ Birth length $(\mathrm{cm})$} \\
\hline Mean & $50 \cdot 3$ \\
\hline $\mathrm{SD}$ & $2 \cdot 2$ \\
\hline \multicolumn{2}{|l|}{ Gestational age (weeks) } \\
\hline$\geq 38$ & $90 \cdot 5$ \\
\hline$<38$ & 9.5 \\
\hline Ever been breast-fed & $99 \cdot 3$ \\
\hline \multicolumn{2}{|l|}{ Mothers } \\
\hline \multicolumn{2}{|l|}{ Age (years) } \\
\hline Mean & $30 \cdot 5$ \\
\hline SD & 4.4 \\
\hline$\leq 24$ & $7 \cdot 3$ \\
\hline $25-34$ & $75 \cdot 2$ \\
\hline$\geq 35$ & $17 \cdot 5$ \\
\hline \multicolumn{2}{|l|}{ Education } \\
\hline Other & $0 \cdot 8$ \\
\hline Lower secondary school or less & $1 \cdot 8$ \\
\hline Upper secondary school & $16 \cdot 5$ \\
\hline College/university ( $<4$ years) & $36 \cdot 9$ \\
\hline College/university ( $\geq 4$ years) & 43.9 \\
\hline \multicolumn{2}{|l|}{$\mathrm{BMI}$} \\
\hline Underweight & 1.5 \\
\hline Normal & 58.6 \\
\hline Overweight & $26 \cdot 4$ \\
\hline Obese & $13 \cdot 1$ \\
\hline \multicolumn{2}{|l|}{ Smoking } \\
\hline No & $96 \cdot 2$ \\
\hline Yes & 3.8 \\
\hline \multicolumn{2}{|l|}{ Marital status } \\
\hline Married & 39.6 \\
\hline Cohabitant & $58 \cdot 3$ \\
\hline Not married/cohabitant & $2 \cdot 1$ \\
\hline \multicolumn{2}{|l|}{ Physically activeł } \\
\hline$\leq 2$ times/week & $63 \cdot 5$ \\
\hline$\geq 3$ times/week & $36 \cdot 5$ \\
\hline \multicolumn{2}{|l|}{ Parents } \\
\hline \multicolumn{2}{|l|}{ Mother tongue } \\
\hline Norwegian & $87 \cdot 1$ \\
\hline Other & $12 \cdot 9$ \\
\hline
\end{tabular}

†Data are presented as percentages for categorical variables, or as means and SD for continuous variables.

$\ddagger$ Physically active to the extent of being out of breath and sweating. started at $94.8 \%$ the first month of life and decreased slowly to $81.0 \%$ at 5 months of age (Fig. 1).

\section{Factors associated with breast-feeding}

Factors associated with any breast-feeding at age 4 and 5 months are presented in Tables 2 and 3. At the age of 4 months, infants of mothers living in a rural area of 500014999 people had lower odds of being breast-fed compared with infants of mothers living in bigger cities ( $\geq 50000$ inhabitants). Further, infants of mothers with overweight/obesity had lower odds of being breast-fed at 4 months of age compared with infants whose mothers had normal BMI (Table 2).

At 5 months, infants with highly educated mothers had higher odds of being breast-fed compared with infants of mothers with less education, as did infants with a married mother compared with other civil status (Table 3).

\section{Factors associated with exclusive breast-feeding}

BMI was associated with exclusive breast-feeding at 4 months of age (Table 2). Infants having mothers who were overweight or obese had lower odds of being exclusively breast-fed compared with infants of normalweight mothers. Higher maternal age was negatively associated with exclusive breast-feeding at 4 months of age. Maternal civil status and degree of urbanization of home place were associated with exclusive breast-feeding at age 4 months.

Parity was significantly associated with exclusive breastfeeding at both 4 months (Table 2) and 5 months (Table 3). Higher parity yielded higher odds of the infant being exclusively breast-fed compared with infants of mothers with only one child. Infants of mothers living in the western part of Norway had higher odds of being exclusively breast-fed at 5 months of age compared with infants in the capital region.

\section{Discussion}

The aim of the current study was to investigate the association between socio-economic factors and maternal BMI, respectively, and exclusive breast-feeding/any breast-feeding among Norwegian infants at 4 and 5 months of age. High maternal education was positively associated with breast-feeding at age 5 months of life. However, there was no significant association between high maternal education and exclusive breast-feeding. Our results show that there are associations between socioeconomic factors such as maternal education related to breast-feeding, but there are also strong associations between maternal BMI and both breast-feeding and exclusive breast-feeding.

The total number of ever breast-fed infants in the present study was high, which is similar to previous studies in Norway ${ }^{(29)}$. However, the percentage of exclusively 


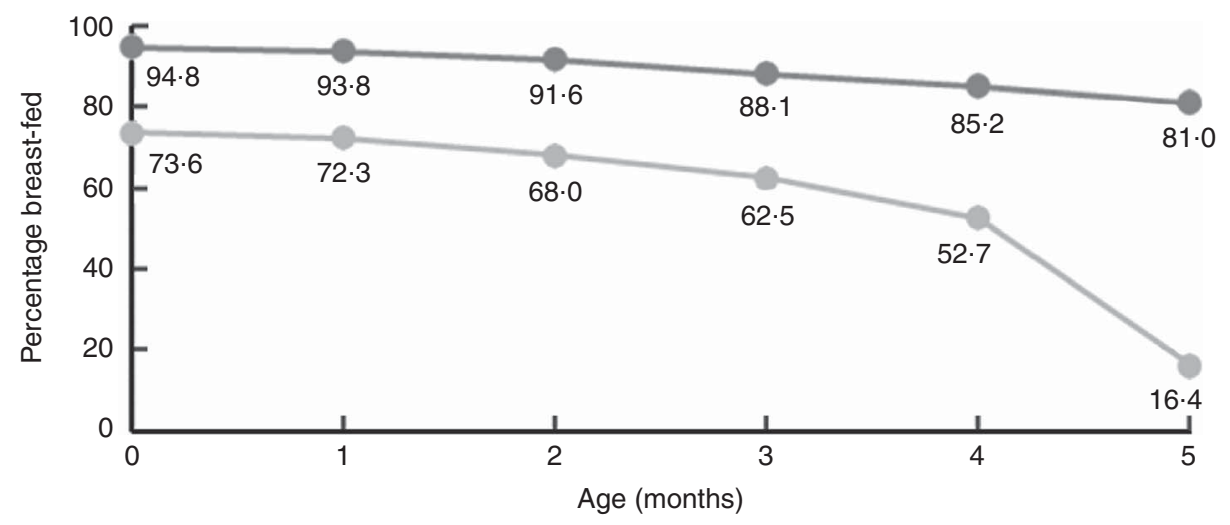

Fig. 1 Any breast-feeding (--) and exclusive breast-feeding (-○) during the first 5 months of life among Norwegian infants ( $n$ 715), Early Food for Future Health study, March-October 2016

Table 2 Adjusted OR and $95 \% \mathrm{Cl}$ of exclusive breast-feeding $(n 600)$ and breast-feeding $(n 700)$ at 4 months of age $†$ among Norwegian infants, Early Food for Future Health study, March-October 2016

\begin{tabular}{|c|c|c|c|c|c|c|c|c|}
\hline \multirow[b]{2}{*}{ Variable } & \multicolumn{4}{|c|}{ Exclusively breast-fed } & \multicolumn{4}{|c|}{ Breast-fed§ } \\
\hline & $n$ & $\%$ & OR & $95 \% \mathrm{Cl}$ & $n$ & $\%$ & OR & $95 \% \mathrm{Cl}$ \\
\hline \multicolumn{9}{|l|}{ Education } \\
\hline Low & 55 & $42 \cdot 0$ & 1 & Ref. & 95 & $72 \cdot 5$ & 1 & Ref. \\
\hline High & 316 & 54.7 & 1.376 & $0.873,2.170$ & 508 & 87.9 & 1.597 & $0.920,2.775$ \\
\hline Age\| & & & $0.945^{\star *}$ & $0.906,0.985$ & & & 0.978 & $0.928,1.030$ \\
\hline \multicolumn{9}{|l|}{ Marital status } \\
\hline Married & 165 & $58 \cdot 3$ & 1 & Ref. & 248 & 87.6 & 1 & Ref. \\
\hline Cohabitant & 207 & $49 \cdot 6$ & $0.689^{*}$ & $0.496,0.959$ & 352 & 84.4 & 0.693 & $0.429,1.119$ \\
\hline Single & 5 & 33.3 & 0.650 & $0 \cdot 194,2 \cdot 171$ & 9 & $60 \cdot 0$ & 0.397 & $0.108,1.465$ \\
\hline \multicolumn{9}{|l|}{ Number of children } \\
\hline 1 & 199 & $49 \cdot 0$ & 1 & Ref. & & & & \\
\hline 2 & 122 & 57.8 & $1.730^{\star *}$ & $1 \cdot 196,2.503$ & & & & \\
\hline$\geq 3$ & 56 & $57 \cdot 7$ & $2.035^{\star *}$ & $1.202,3.447$ & & & & \\
\hline \multicolumn{9}{|l|}{$\mathrm{BMI}$} \\
\hline Normal & 250 & 59.7 & 1 & Ref. & 377 & $90 \cdot 0$ & 1 & Ref. \\
\hline Underweight & 6 & 54.5 & 0.878 & $0.250,3.079$ & 10 & $90 \cdot 9$ & 1.308 & $0.158,10.838$ \\
\hline Overweight & 84 & 44.7 & $0.542^{\star \star}$ & $0.375,0.784$ & 152 & 80.9 & $0.555^{\star}$ & $0.333,0.925$ \\
\hline Obese & 35 & 37.6 & $0.424^{\star *}$ & $0.259,0.694$ & 67 & $72 \cdot 0$ & $0.419^{\star \star}$ & $0.228,0.769$ \\
\hline \multicolumn{9}{|l|}{ Smoking } \\
\hline No & 370 & $53 \cdot 8$ & 1 & Ref. & 591 & 85.9 & 1 & Ref. \\
\hline Yes & 7 & 25.9 & 0.412 & $0.164,1.036$ & 18 & $66 \cdot 7$ & 0.711 & $0.274,1.842$ \\
\hline \multicolumn{9}{|c|}{ Unforeseen expense } \\
\hline Able to pay & 366 & 53.5 & 1 & Ref. & 591 & $86 \cdot 4$ & 1 & Ref. \\
\hline Not able/maybe & 11 & 35.5 & 0.746 & $0.332,1.677$ & 18 & $58 \cdot 1$ & 0.497 & $0.207,1.194$ \\
\hline \multicolumn{9}{|l|}{ Running expenses } \\
\hline Problems & & & & & 79 & 72.5 & 1 & Ref. \\
\hline Not problems & & & & & 530 & 87.5 & 0.640 & $0.365,1.122$ \\
\hline \multicolumn{9}{|c|}{ Degree of urbanization } \\
\hline$\geq 50000$ & 162 & 54.0 & 1 & Ref. & 272 & $90 \cdot 7$ & 1 & Ref. \\
\hline $15000-49999$ & 89 & $60 \cdot 1$ & 1.225 & $0.801,1.873$ & 127 & $85 \cdot 8$ & 0.649 & $0.345,1.219$ \\
\hline $5000-14999$ & 82 & 54.6 & $0.652^{*}$ & $0.432,0.984$ & 141 & $78 \cdot 3$ & $0.435^{\star *}$ & $0.245,0.771$ \\
\hline$\leq 4999$ & 44 & $50 \cdot 6$ & 1.032 & $0.617,1.726$ & 69 & $79 \cdot 3$ & 0.563 & $0.277,1.144$ \\
\hline
\end{tabular}

Ref., referent category.

${ }^{*} P<0.05,{ }^{* \star} P<0.01$.

†Two models are presented with different covariates included; this explains the open spaces in the table.

$\ddagger$ Adjusted for maternal education, maternal age, marital status, number of children, maternal BMI, smoking status, ability to pay an unforeseen expense of 3000 NOK and degree of urbanization.

$\S$ Adjusted for maternal education, maternal age, marital status, maternal BMI, smoking status, ability to pay an unforeseen expense of $3000 \mathrm{NOK}$, problems with running expenses and degree of urbanization.

|| Maternal age in years.

breast-fed infants was $16 \cdot 4 \%$ at 5 months, which is 10 percentage points lower than what has been reported in earlier studies carried out in Norway ${ }^{(15)}$. This could indicate a real change over time or it could reflect selection bias. The current study recruited participants from all over Norway, but the sample is skewed towards a more well-educated population and could be different from the national study. 
Table 3 Adjusted OR and $95 \% \mathrm{Cl}$ of exclusive breast-feeding $(n 703)$ and breast-feeding $(n 700)$ at 5 months of age $\dagger$ among Norwegian infants, Early Food for Future Health study, March-October 2016

\begin{tabular}{|c|c|c|c|c|c|c|c|c|}
\hline \multirow[b]{2}{*}{ Variable } & \multicolumn{4}{|c|}{ Exclusively breast-fed $\ddagger$} & \multicolumn{4}{|c|}{ Breast-fed§ } \\
\hline & $n$ & $\%$ & OR & $95 \% \mathrm{Cl}$ & $n$ & $\%$ & OR & $95 \% \mathrm{Cl}$ \\
\hline \multicolumn{9}{|l|}{ Education } \\
\hline Low & 20 & $15 \cdot 3$ & 1 & Ref. & 82 & $62 \cdot 6$ & 1 & Ref. \\
\hline High & 94 & $16 \cdot 3$ & 1.232 & $0.687,2.207$ & 491 & 84.9 & $2 \cdot 061^{\star *}$ & $1.243,3.419$ \\
\hline Age\| & & & 0.987 & $0.932,1.045$ & & & 1.000 & $0.953,1.050$ \\
\hline \multicolumn{9}{|l|}{ Marital status } \\
\hline Married & 60 & 21.2 & 1 & Ref. & 244 & $86 \cdot 2$ & 1 & Ref. \\
\hline Cohabitant & 56 & 13.4 & 0.711 & $0.459,1.101$ & 327 & 78.4 & $0.581^{\star *}$ & $0.373,0.903$ \\
\hline Single & 1 & $6 \cdot 7$ & 0.302 & $0.037,2.442$ & 8 & $53 \cdot 3$ & 0.342 & $0.098,1.193$ \\
\hline \multicolumn{9}{|l|}{ Number of children } \\
\hline 1 & 48 & 11.8 & 1 & Ref. & & & & \\
\hline 2 & 40 & 19.0 & 1.586 & $0.967,2.599$ & & & & \\
\hline$\geq 3$ & 29 & 29.9 & $2 \cdot 812^{\star \star}$ & $1.486,5 \cdot 320$ & & & & \\
\hline \multicolumn{9}{|c|}{$1.400,0.0<0$} \\
\hline Normal & & & & & 358 & 85.4 & 1 & Ref. \\
\hline Underweight & & & & & 9 & $81 \cdot 8$ & 0.971 & $0.197,4.783$ \\
\hline Overweight & & & & & 144 & $76 \cdot 6$ & 0.695 & $0.437,1.107$ \\
\hline Obese & & & & & 66 & 71.0 & 0.603 & $0.337,1.078$ \\
\hline \multicolumn{9}{|l|}{ Smoking } \\
\hline No & & & & & 565 & $82 \cdot 1$ & 1 & Ref. \\
\hline Yes & & & & & 14 & 51.9 & 0.452 & $0.186,1.095$ \\
\hline \multicolumn{9}{|c|}{ Unforeseen expense } \\
\hline Able to pay & & & & & 563 & $82 \cdot 3$ & 1 & Ref. \\
\hline Not able/maybe & & & & & 16 & 51.6 & 0.476 & $0.201,1.124$ \\
\hline \multicolumn{9}{|l|}{ Running expenses } \\
\hline Problems & & & & & 75 & $68 \cdot 8$ & 1 & Ref. \\
\hline Not problems & & & & & 504 & 83.2 & 0.744 & $0.435,1.278$ \\
\hline \multicolumn{9}{|l|}{ Geographic region } \\
\hline Capital & 6 & 5.9 & 1 & Ref. & & & & \\
\hline East & 33 & $17 \cdot 6$ & $2 \cdot 189$ & $0.799,5.998$ & & & & \\
\hline South & 18 & $18 \cdot 0$ & 2.414 & $0.863,6.751$ & & & & \\
\hline West & 46 & $21 \cdot 7$ & $2.750^{*}$ & $1.062,7.124$ & & & & \\
\hline Middle & 6 & $9 \cdot 8$ & 1.080 & $0.301,3.873$ & & & & \\
\hline North & 8 & $14 \cdot 8$ & 1.602 & $0.475,5.403$ & & & & \\
\hline \multicolumn{9}{|c|}{ Degree of urbanization } \\
\hline$\geq 50000$ & 36 & $12 \cdot 0$ & 1 & Ref. & 253 & $84 \cdot 3$ & 1 & Ref. \\
\hline $15000-49999$ & 31 & $20 \cdot 9$ & 1.671 & $0.915,3.052$ & 127 & 85.8 & 1.273 & $0.710,2 \cdot 281$ \\
\hline $5000-14999$ & 30 & $16 \cdot 7$ & 1.055 & $0.574,1.938$ & 137 & $76 \cdot 1$ & 0.768 & $0.460,1.283$ \\
\hline$\leq 4999$ & 20 & $23 \cdot 0$ & $2.084^{*}$ & $1.060,4.094$ & 62 & $71 \cdot 3$ & 0.680 & $0.367,1.264$ \\
\hline
\end{tabular}

Ref., referent category.

${ }^{\star} P<0.05,{ }^{* \star} P<0.01$.

†Two models are presented with different covariates included; this explains the open spaces in the table.

$\ddagger$ Adjusted for maternal education, maternal age, marital status, number of children, geographic region and degree of urbanization.

$\S$ Adjusted for maternal education, maternal age, marital status, maternal BMI, smoking status, ability to pay an unforeseen expense of $3000 \mathrm{NOK}$, problems with running expenses and degree of urbanization.

\|Maternal age in years.

\section{Maternal education}

Several studies have found a significant association between maternal education and the duration of exclusive breast-feeding or any breast-feeding ${ }^{(15,30)}$. In the present study, we found no significant association between maternal education and exclusive breast-feeding. Similar results were also found in an Icelandic study ${ }^{(31)}$. However, the odds of being breast-fed at 5 months was significantly higher for infants of mothers with high education.

Maternal education is often used to describe socioeconomic status because it reflects both knowledge and economy ${ }^{(32)}$. Cognitive function could be affected by the knowledge and skills achieved through education and may therefore make people with higher education more receptive to health education messages ${ }^{(32)}$. Health promotion interventions such as breast-feeding promotion may therefore be more efficient in groups with higher education.

\section{Degree of urbanization}

The current study found that infants of mothers living in smaller communities (5000-14999 inhabitants), compared with infants living in bigger cities ( $\geq 50000$ inhabitants), had lower odds of being both breast-fed and exclusively breast-fed at 4 months. The same association was found by Lande et al., who showed that an increased number of inhabitants yielded higher odds of being exclusively breast-fed at 4 and 6 months of age ${ }^{(29)}$. Allen et al. found that hospitals in less urbanized counties scored lower on breast-feeding assistance, staff training, and structural and 
organizational aspects of care. They suggested that the differences in breast-feeding rates could be affected by the differences in maternity care practices supportive of breast-feeding ${ }^{(33)}$. In the current study, infants of mothers living in the smallest communities had higher odds of being exclusively breast-fed at 4 and 5 months of age, compared with infants of mothers living in bigger cities ( $\geq 50000$ inhabitants). However, there were few participants in these groups and the association could therefore be affected by the small selection in this group.

\section{Maternal BMI}

Maternal overweight and obesity has been reported to be negatively associated with breast-feeding duration and initiation $^{(22,34)}$. Our study supports these findings, as infants of overweight or obese mothers had lower odds of being both breast-fed and exclusively breast-fed at several of the studied ages, compared with infants of mothers with normal BMI. Maternal overweight can be a barrier to successful breast-feeding due to physical problems from their large size and possibly a decrease in their first phase of milk production ${ }^{(35)}$. Overweight and obesity also increases the risk of caesarean delivery ${ }^{(35)}$ which previous studies have found to be associated with early cessation of full breastfeeding (full breast-feeding: infants could have received water, water-based drinks and fruit juice additional to breast milk) ${ }^{(36)}$. A study on predictors of breast-feeding in overweight and obese mothers pointed out that overweight and obese mothers might need additional encouragement to initiate and continue breast-feeding ${ }^{(23)}$. This might contribute to reduce the inequities in breast-feeding.

\section{Maternal age}

Maternal age has been observed as being significantly associated with duration of both exclusive breast-feeding and any breast-feeding in earlier studies ${ }^{(15,37)}$. Our results do not support these findings from previous studies in Norway or other industrialized countries. We found that infants of mothers with higher age had lower odds of being exclusively breast-fed at 4 months of age; however, this was not found at 5 months, and for any breast-feeding we found no associations with maternal age. One could speculate whether the older mothers are more aware of the recent discussions regarding potential benefits of introducing food at this age.

\section{Parity}

Previously there has been inconsistent results regarding the association between parity and breast-feeding ${ }^{(27)}$. In our study, infants of mothers with previous children had higher odds of being exclusively breast-fed. However, we found no significant association between parity and being breast-fed. Hass et al. found that prior breast-feeding experience was a predictor of continued breast-feeding at 6 weeks postpartum ${ }^{(38)}$.

\section{Maternal smoking}

Our study does not support previous results from Norway concerning an association between smoking and breastfeeding $^{(15)}$, as we did not find a significant association between smoking and breast-feeding or exclusive breastfeeding. The number of smoking mothers participating in the current study was low and might have affected our results.

\section{Strengths and limitations}

Recruitment of the participants was made via social media and through health-care clinics; thus the participants were not selected, but were voluntarily recruited. This led to an uncertainty over who we were able to recruit from those who were potentially eligible and how many who were actually invited. The study sample was dominated by highly educated mothers. The difference in participation between highly and lower educated mothers may have resulted in an underestimation of socio-economic differences in breast-feeding. This leads to a selection bias that weakens the current research's generalizability to a greater population. The data were self-reported, which reduces the reliability, especially for questions about BMI and breast-feeding. The questionnaires were filled in retrospectively at infant age 6 months, thus asking the parents about their infant's nutrition in the last 6 months could lead to a recall bias. Further, for the data in Tables 2 and 3 presenting findings for the association between BMI category and breast-feeding, one should acknowledge that there were few underweight participants, so these estimates should be read with caution. Also, we included all participants in the analysis regardless of gestational age. Children born preterm may have difficulties being breastfed, so one could argue that they should have been excluded from the analysis. We therefore ran a sensitivity test by excluding those born before week 38 and the results did not change (data not shown), so we decided to have them included. A strength to our study is the inclusion of a comparatively large number of participants and the broad use of variables for socio-economic status. The FFQ was developed for Early Food for Future Health and was based on questionnaires used in national surveys in Norway ${ }^{(39)}$. We acknowledge that other factors can affect breast-feeding such as time of initiating breast-feeding ${ }^{(40)}$, breast-feeding difficulties ${ }^{(30)}$ and postpartum depression $^{(41)}$; however, we did not have specific information about these conditions in our study except from data on depression symptoms, which could be explored further.

\section{Conclusion}

Despite the Norwegian long-term public health policy to reduce social differences in health, factors like maternal education are still associated with inequality in breastfeeding duration. Our results also show a lower rate of exclusively breast-fed infants after 4 months of age 
compared with previous studies, with only $16.4 \%$ of infants exclusively breast-feeding at 5 months of age. Infants of mothers with overweight/obesity had lower odds of being exclusively breast-fed at 4 months compared with infants of normal-weight mothers in our study. Infants of highly educated mothers had higher odds of being breast-fed compared with infants of lower educated mothers. Breast-feeding promotion should still focus on lower educated mothers to reduce the social gap in diet and health, but should also target overweight and obese mothers to increase the rates of exclusively breast-fed infants in Norway.

\section{Acknowledgements}

Financial support: This work was supported by the University of Agder and the Eckbo-foundation. The funders had no role in the design, analysis or writing of this article. Conflict of interest: No conflicts of interest were reported. Authorship: N.C.Ø. and E.R.H. conceived the study. C.H., E.R.H. and N.C. $\varnothing$. developed the study. C.H. managed the data collection. V.K.B. analysed the data and drafted the paper. N.C. $\varnothing$. contributed with counselling and revision of the paper. All authors commented critically on the paper and helped with interpreting the data. Each author has seen and approved the contents of the submitted manuscript. Etbics of buman subject participation: This study was conducted according to the guidelines laid down in the Declaration of Helsinki and all procedures involving human subjects were approved by The Norwegian Social Science Data Services. Written informed consent was obtained from all subjects.

\section{References}

1. Butte NF, Lopez-Alarcon MG \& Garza C (2002) Nutrient adequacy of exclusive breastfeeding for the term infant during the first six months of life. http://www.who.int/nutrition/publica tions/infantfeeding/9241562110/en/ (accessed January 2017).

2. Bernt KM \& Walker WA (1999) Human milk as a carrier of biochemical messages. Acta Paediatr Suppl 88, 27-41.

3. World Health Organization (2013) Short-Term Effects of Breastfeeding - A Systematic Review on the Benefits of Breastfeeding on Diarrboea and Pneumonia Mortality. Geneva: WHO; available at http://apps.who.int/iris/bitstream/ 10665/95585/1/9789241506120_eng.pdf?ua =1

4. World Health Organization (2013) Long-Term Effects of Breastfeeding - A Systematic Review. Geneva: WHO; available at http://apps.who.int/iris/bitstream/10665/79198/1/ 9789241505307_eng.pdf?ua=1

5. Silva MdCM, Assis AMO, Pinheiro SMC et al. (2015) Breastfeeding and maternal weight changes during 24 months postpartum: a cohort study. Matern Child Nutr 11, 780-791.

6. Feng LP, Chen HL \& Shen MY (2014) Breastfeeding and the risk of ovarian cancer: a meta-analysis. J Midwifery Womens Health 59, 428-437.

7. Pechlivani F \& Vivilaki V (2012) Breastfeeding and breast cancer. Health Sci J 6, 610-617.

8. World Health Organization (2017) Babies and mothers worldwide failed by lack of investment in breastfeeding. http://www.who.int/mediacentre/news/releases/2017/lackinvestment-breastfeeding/en/ (accessed October 2017).

9. The Norwegian Directorate of Health (2017) The Norwegian Dietary Guidelines for Infant Nutrition (in Norwegian). http://www.helsedirektoratet.no/retningslinjer/spedbarnser nering/seksjon?Tittel=anbefalinger-for-morsmelk-morsmelk erstatning-1054\# råd-om-morsmelk-og-annen-mat-måtilpasses-hvert-barn-og-hver-mor (accessed January 2017).

10. The Norwegian Directorate of Health (2016) Exclusive breastfeeding till six months still recommended - however, a more individual approach is needed (in Norwegian). http://www.helsedirektoratet.no/nyheter/fortsatt-fullammingtil-seks-maneder-men-mer-individuell-tilpasning (accessed January 2017).

11. Drago R, Hayes J \& Yi Y (2010) Better Health for Mothers and Children: Breastfeeding Accommodations under the Affordable Care Act, p. 3. Washington, DC: Institute for Women's Policy Research; available at https://iwpr.org/wpcontent/uploads/wpallimport/files/iwpr-export/publications/ B292.pdf

12. NAV (2017) Parental benefit. http://www.nav.no/en/Home/ Benefits+and+services/Relatert+informasjon/parental-benefit (accessed January 2017).

13. Lande B \& Helleve A (2014) Breastfeeding and Infant Nutrition. A National Survey 2013 (in Norwegian). Oslo: The Norwegian Directorate of Health.

14. Grewal NK, Andersen LF, Sellen D et al. (2016) Breastfeeding and complementary feeding practices in the first 6 months of life among Norwegian-Somali and NorwegianIraqi infants: the InnBaKost survey. Public Health Nutr 19, 703-715.

15. Kristiansen AL, Lande B, Overby NC et al. (2010) Factors associated with exclusive breast-feeding and breast-feeding in Norway. Public Health Nutr 13, 2087-2096.

16. Public Health Report (2015) White Paper 19 (2014-2015) (in Norwegian). http://www.regjeringen.no/no/dokumenter/ meld.-st.-19-2014-2015/id2402807/sec2 (accessed December 2016).

17. Flacking R, Nyqvist KH \& Ewals U (2007) Effects of socioeconomic status on breastfeeding duration in mothers of preterm and term infants. Eur J Public Health 17, 579-584.

18. The Norwegian Ministries (2017) National Action Plan to Improve Public Diet (in Norwegian). Oslo: The Norwegian Ministries.

19. World Health Organization (2016) Obesity and overweight, Fact sheet. http://www.who.int/mediacentre/factsheets/ fs311/en/ (accessed March 2017).

20. Statistics Norway (2016) Health, Care and Social Relations, Survey on Living Conditions, 2015. Oslo: Statistics Norway.

21. World Health Organization (2015) Health in 2015: From MDGs, Millennium Development Goals to SDGs, Sustainable Development Goals. Geneva: WHO; available at http:// apps.who.int/iris/bitstream/10665/200009/1/9789241565110_ eng.pdf?ua $=1$

22. Winkvist A, Brantsæter AL, Brandhagen M et al. (2015) Maternal prepregnant body mass index and gestational weight gain are associated with initiation and duration of breastfeeding among Norwegian mothers. J Nutr 145, 1263-1270.

23. Krause KM, Lovelady CA \& Østbye T (2010) Predictors of breastfeeding in overweight and obese women: data from Active Mothers Postpartum (AMP). Matern Child Health J 15, 367-375.

24. World Health Organization (2017) BMI classification. http:// www.apps.who.int/bmi/index.jsp?introPage=intro_3.html (accessed March 2017).

25. The American Heritage ${ }^{\circledR}$ Medical Dictionary (2007) Parity. http://www.medical-dictionary.thefreedictionary.com/parity (accessed March 2017). 
26. World Health Organization (2017) Exclusive breastfeeding. http://www.who.int/elena/titles/exclusive_breastfeeding/en/ (accessed January 2017).

27. Thulier D \& Mercer J (2009) Variables associated with breastfeeding duration. J Obstet Gynecol Neonatal Nurs 38, 259-268.

28. Scott JA \& Binns CW (1998) Factors associated with the initiation and duration of breastfeeding: a review of the literature. Aust J Nutr Diet 55, 51-62.

29. Lande B, Andersen LF, Bærug A et al. (2003) Infant feeding practices and associated factors in the first six months of life: the Norwegian infant nutrition survey. Acta Paediatr 92, 152-161.

30. Bærug A, Laake P, Løland BF et al. (2017) Explaining socioeconomic inequalities in exclusive breast feeding in Norway. Arch Dis Child 102, 708-714.

31. Thorisdottir AV, Gunnarsdottir I \& Thorsdottir I (2013) Revised infant dietary recommendations: the impact of maternal education and other parental factors on adherence rates in Iceland. Acta Paediatr 102, 143-148.

32. Solar O \& Irwin AA (2010) A Conceptual Framework for Action on the Social Determinants of Health. Social Determinants of Health Discussion Paper 2 (Policy and Practice). Geneva: WHO.

33. Allen JA, Perrine CG \& Scanlon KS (2015) Breastfeeding supportive hospital practices in the US differ by county urbanization level. J Hum Lact 31, 440-442.

34. Baker JL, Michaelsen KF, Sørensen TIA et al. (2007) High prepregnant body mass index is associated with early termination of full and any breastfeeding in Danish women. Am J Clin Nutr 86, 404-411.

35. Catalano PM \& Shankar K (2017) Obesity and pregnancy: mechanisms of short term and long term adverse consequences for mother and child. BMJ 360, j1.

36. Häggkvist AP, Brantsæter AL, Grjibovski AM et al. (2010) Prevalence of breast-feeding in the Norwegian Mother and Child Cohort Study and health service-related correlates of cessation of full breast-feeding. Public Health Nutr 13, 2076-2086.

37. Biro MA, Yelland JS \& Brown SJ (2014) Why are young women less likely to breastfeed? Evidence from an Australian population-based survey. Birth 41, 245-253.

38. Hass DM, Howard CS, Christopher M et al. (2006) Assessment of breastfeeding practices and reasons for success in a military community hospital. J Hum Lact 22, 439-445.

39. Øverby NC, Kristiansen AL, Frost Andersen L et al. (2008) "Spedkost 6 months". National Dietary Survey in 6 Months Old Infants (in Norwegian). Oslo: The Norwegian Directorate of Health, Norwegian Food Safety Authority and University of Oslo.

40. NEOVITA Study Group (2016) Timing of initiation, patterns of breastfeeding, and infant survival: prospective analysis of pooled data from three randomised trials. Lancet Glob Health 4, e266-e275.

41. Dias CC \& Figueiredo B (2015) Breastfeeding and depression: a systematic review of the literature. J Affect Disord 171, 142-154. 